\title{
Experimental and numerical evaluation on debonding of fully grouted rockbolt under pull-out loading
}

\author{
Shuisheng $\mathrm{Yu}^{1,2} \cdot$ Wancheng $\mathrm{Zhu}^{1}{ }^{10} \cdot$ Leilei Niu $^{1}$
}

Received: 15 September 2021 / Accepted: 2 February 2022

(c) The Author(s) 2022

\begin{abstract}
The axial loading in rockbolts changes due to stress redistribution and rheology in the country rock mass. Such a change may lead to debonding at rockbolt to grout interface or rupture of the rockbolt. In this study, based on laboratory experiments, ultrasonic guided wave propagation in fully grouted rockbolt under different pull-out loads was investigated in order to examine the resultant debonding of rockbolt. The signals obtained from the ultrasonic monitoring during the pull-out test were processed using wavelet multi-scale analysis and frequency spectrum analysis, the signal amplitude and the amplitude ratio $(Q)$ of low frequency to high frequency were defined to quantify the debonding of rockbolt. In addition to the laboratory test, numerical simulation on the effect of the embedment lengths on ultrasonic guided wave propagation in rockbolt was conducted by using a damage-based model, and the debonding between rockbolt and cement mortar was numerically examined. It was confirmed that the ultrasonic guided wave propagation in rockbolt was very sensitive to the debonding because of pull-out load, therefore, the critical bond length could be calculated based on the propagation of guided wave in the grouted rockbolt. In time domain, the signal amplitude in rockbolt increased with pull-out load from 0 to $100 \mathrm{kN}$ until the completely debonding, thus quantifying the debonding under the different pull-out loads. In the frequency domain, as the $Q$ value increased, the debonding length of rockbolt decreased exponentially. The numerical results confirmed that the guided wave propagation in the fully grouted rockbolt was effective in detecting and quantifying the debonding of rockbolt under pull-out load.
\end{abstract}

Keywords Fully grouted rockbolt · Debonding $\cdot$ Pull-out load $\cdot$ Ultrasonic guided wave propagation

\section{Introduction}

As an important part of the support system, rockbolt is widely used for the reinforcement and support of slopes and roadways (Wang et al. 2009). In geotechnical and mining engineering, it is imperative to use effective and nondestructive scientific methods to test rockbolt bond quality, because rockbolts cannot be observed directly, and deterioration of the surrounding environment can increase the occurrence of rock burst and landslide. For the detection of

Wancheng Zhu

zhuwancheng@mail.neu.edu.cn

1 Center for Rock Instability and Seismicity Research, Department of Mining Engineering, School of Resource and Civil Engineering, Northeastern University, Shenyang 110819, China

2 School of Architectural Engineering, Zhongyuan University of Technology, Zhengzhou 450007, China rockbolt bond quality, Beard and Lowe (2003) and Beard et al. (2003) used numerical simulation methods to determine the wave attenuation at low and high frequencies in the rockbolts, and analyzed the influence on wave attenuation of the elastic modulus, the thickness of the anchorage grout, and the quality of the rockbolt/grout interface. Ivanović and Neilson (2013) studied potential damage in grouted rockbolts and determined the effective bond length. The rockbolt bond integrity could be evaluated using ultrasonic guided wave and hammer impact (Lee et al. 2012; Suits et al. 2008; Yu et al. 2013, 2016). The energy transfer in rockbolt was studied by experimentally and numerically, and the results showed that the length of rockbolts and the thickness of anchorage grout could be determined according to the wave propagation signal received at the free end of the rockbolt (Zima and Rucka 2017). Zima and Rucka (2018) studied the influence of the location of debonding on the wave conversion and diffraction. Zou et al. (2010) analyzed the effects of grout strength and air content in the grout on 
the rockbolt bond quality, and showed that the guided wave rapidly attenuated with an increase in grout strength, and the group velocity increased with the quantity of the air content. Cui and Zou (2012) studied the attenuation of ultrasonic guided wave in grouted rockbolt using numerical simulation and experimentally confirmed the influence of rockbolt defect and lack of mortar on grouted rockbolt.

Debonding of rockbolt can be detected by analyzing the ultrasonic guided wave propagation in rockbolt, and the difficulty is that the reflected waves at various interfaces exist in a mixed and complex form in the detected signal, the detection signal is observed in the time domain, and is mainly expressed as low-frequency signal, and the high-frequency component is covered (Xiao et al. 2006). Therefore, it is difficult to directly obtain the arrival time of the reflected wave from the actual detection signal and signal processing is required to obtain a reasonable signal. Fourier and wavelet transform processes have been used for this type of signal analysis (Lee et al.2012; Bouden et al. 2012; Kwun et al. 1998; Chen and Wissawapaisal 2002; Rizzo 2006; Chen and Wilcox 2007; Chaki and Bourse 2009a, b). Lee et al. (2012) used Fourier and wavelet transform to evaluate rockbolt integrity and concluded that the magnitude of the spectral rate, the energy velocity, and the phase velocity could be used as indicators of integrity. Kwun et al. (1998) investigated the effect of tensile loading on the longitudinal mode elastic wave propagation in seven-wire strands. The results indicated that a certain portion of the frequency components of the wave was highly attenuated and absent in the frequency spectrum of the wave. Chen and Wissawapaisal (2002) reported that the traveling time of the stress wave in the wire strand was affected due to the elongation of the strand and the changes in wave velocities when the strand was subjected to tensile force. Rizzo (2006) conducted experiments on ultrasonic wave propagation in seven-wire strands loaded at different stress levels and reported that the ultrasonic features were sensitive to the variation of applied load. Chen and Wilcox (2007) analyzed the influence of load on guided wave propagation, and found that the guided wave phase velocity increased and the group velocity decreased with increased applied load. The research results of Chaki and Bourse (2009a, b) illustrated the potential and suitability of the guided wave method to evaluate the stress levels in seven-wire steel strands.

With regard to the numerical simulation on the wave propagation in rockbolt, many scholars used idealized ultrasonic guided wave packets as the excitation signal in the numerical simulation of rockbolt detection (Liu et al. 2017; Ni and Iwamoto 2002; Sun et al. 2006; Ren and Li 2009). Liu et al. (2017) analyzed the influence of tensile stress on ultrasonic guided waves propagation in steel cables based on the fast Fourier transform. The results showed increased ultrasonic guided wave energy with increased tensile force. Ren and Li (2009) used wavelet multi-scale analysis to obtain the reflection signal of the rockbolt bottom in the low-frequency component and detail signals in the high-frequency component.

In the above studies, it could be seen that the majority of the past studies were on the non-destructive testing of the bond quality of rockbolt in the absence of external loading using the guided wave technique, this is inconsistent with the fact that the rockbolt is under stress in actual engineering. The mining stress field in the rock mass usually varies due to the on-going mining operations, leading to the variation of the axial loading in the rockbolt, therefor, it is necessary to detect the debonding length of rockbolt under various pull-out loads to ensure the safety and avoid the accident of grouted rockbolt systems. This study aimed to evaluate the debonding of rockbolt under different pull-out load according to the analysis of ultrasonic guided wave propagation. In this regards, the Pull-out Testing Machine (PTM) is used to test the bond quality of rockbolt under different pull-out loads. The wavelet multi-scale analysis and frequency spectrum analysis were used for processing the signal obtained from the guided wave propagation to calculate the debonding length of the rockbolt and evaluate the bond quality. Finally, grouted rockbolt system with different bond lengths was analyzed by numerical simulation, and the debonding under various levels of pull-out loadings was further examined.

\section{Guided wave propagation and wavelet transform theory}

\subsection{Guided wave propagation theory}

\subsubsection{Guided wave propagation in free rockbolt}

Determination of the frequency dependent dispersion curve in ultrasonic guided wave is required for non-destructive testing (Hayashi et al. 2004). The dispersion curve represents the fundamental information of the guided wave propagation: wavelength, phase velocity, and group velocity, which can be expressed by the Pochhammer-Chree frequency dispersion equation of a longitudinal guided wave (Hayashi et al. 2004):

$$
\begin{aligned}
& \frac{2 \alpha}{a}\left(\beta^{2}+k^{2}\right) J_{1}(\alpha a) J_{1}(\beta a)-\left(\beta^{2}-k^{2}\right)^{2} J_{0}(\alpha a) J_{1}(\beta a) \\
& \quad-4 k^{2} \alpha \beta J_{1}(\alpha a) J_{0}(\beta a)=0
\end{aligned}
$$

where, $J_{n}()$ is the $n$-order first Bessel function; $a$ is the rockbolt diameter, and the parameters $\alpha$ and $\beta$ can be defined as:

$\alpha^{2}=\frac{\omega^{2}}{c_{\mathrm{L}}^{2}}-k^{2}$ 
$\beta^{2}=\frac{\omega^{2}}{c_{\mathrm{T}}^{2}}-k^{2}$

where, $k$ is the wave number; $\omega$ is the circular frequency; $c_{\mathrm{L}}$ is the longitudinal wave velocity, and $c_{\mathrm{T}}$ is the transverse wave velocity. Namely,

$c_{\mathrm{L}}=\sqrt{\frac{E(1+v)}{\rho(1+v)(1-2 v)}}$

$c_{\mathrm{T}}=\sqrt{\frac{E}{2 \rho(1+v)}}$

where $E$ is the elastic modulus, $\rho$ is the density, and $v$ is Poisson's ratio.

During guided wave propagation, the guided wave group velocity $\left(c_{\mathrm{g}}\right)$ in rockbolt is

$c_{\mathrm{g}}=\frac{\mathrm{d} \omega}{\mathrm{d} k}$

According to the material parameters listed in Table 1, the Pochhammer-Chree frequency dispersion equation can be solved to obtain the frequency dispersion curve of the guided wave group velocity in free rockbolt. In the low frequency range, only the guided wave of $L(0,1)$ mode appeared, and the guided wave of other modes exhibited a cut-off frequency. Below the cut-off frequency, the guided wave attenuated rapidly and could not propagate any longer, and above the cut-off frequency, the guided wave began to propagate. Therefore, a frequency segment with a single mode was selected to facilitate the signal analysis. As shown in Fig. 1a, when the frequency was $145 \mathrm{kHz}$, the guided wave of $L(0,2)$ mode appeared, thus adding complexity to the signal analysis. For the free rockbolt, there was only one mode of guided wave with the frequency ranging from 0 to $145 \mathrm{kHz}$, and it is conducive to signal analysis.

\subsubsection{Guided wave propagation in grouted rockbolt}

The Pochhammer-Chree frequency dispersion equation with the parameters listed in Table 2 was used to get the frequency dispersion curve of the guided wave group velocity in grouted

Table 1 Material properties of the rockbolt, concrete and cement mortar

\begin{tabular}{llll}
\hline Ingredient & Density $\left(\mathrm{kg} / \mathrm{m}^{3}\right)$ & $\begin{array}{l}\text { Elastic } \\
\text { modulus } \\
(\mathrm{GPa})\end{array}$ & Poisson's ratio \\
\hline Rockbolt & 7850 & 210 & 0.30 \\
Cement mortar & 2100 & 20 & 0.19 \\
Concrete & 2300 & 33 & 0.23 \\
\hline
\end{tabular}

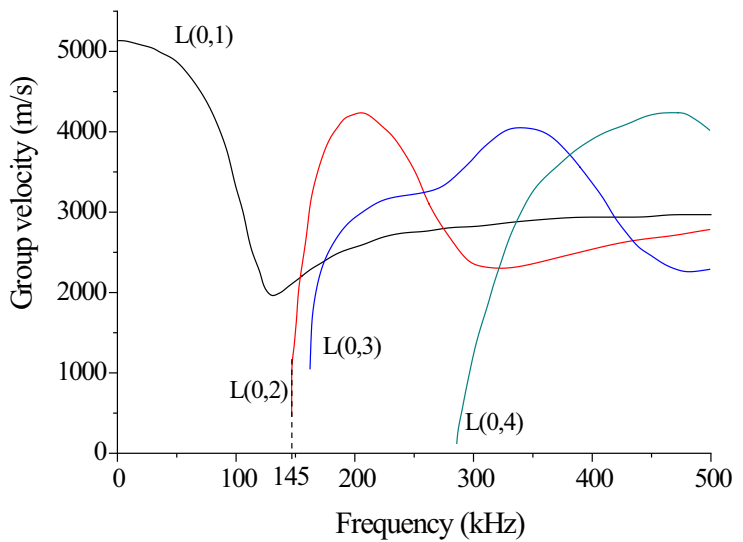

(a) in free rockbolt

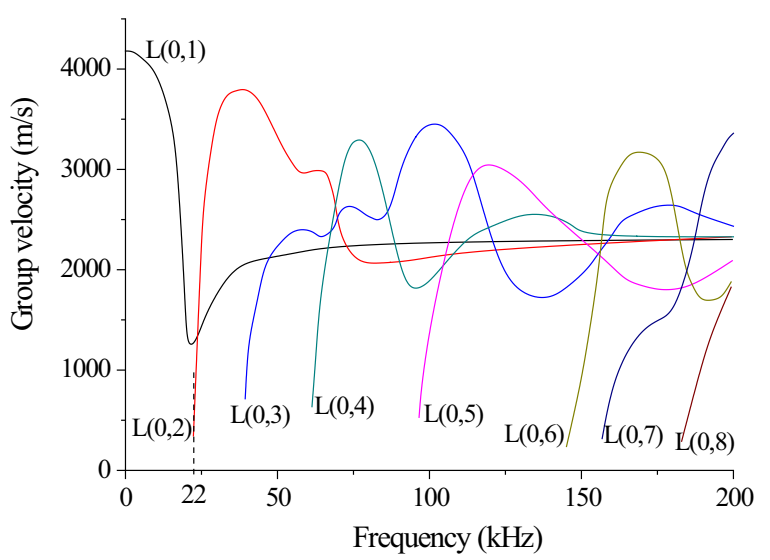

(b) in grouted rockbolt

Fig. 1 Frequency dispersion curves of group velocity of guided wave in rockbolt

rockbolt (Fig. 1b). Within the frequency range from 0 to $200 \mathrm{kHz}$, there were eight modes in propagation process of the guided wave. Due to the rapid attenuation of the guided wave energy in the grouted rockbolt, the guided wave frequency decreased. Thus, within the frequency ranging from 0 to $22 \mathrm{kHz}$, only mode $L(0,1)$ existed, and it was conducive to signal analysis.

\subsection{Wavelet transform theory}

The bond quality and debonding of rockbolt is detected by ultrasonic guided wave, and in its detection signal, the reflected waves at various interfaces existed in mixed and complex forms. In the time domain, the detection signal is

Table 2 Mix proportions of concrete and cement mortar in test

\begin{tabular}{lllll}
\hline Ingredient & Water & Cement & Sand & Stone \\
\hline Concrete & 0.47 & 1 & 1.3 & 3.02 \\
Cement mortar & 1 & 1 & 3.2 & 0 \\
\hline
\end{tabular}


mainly represented by low-frequency signal, while the highfrequency component is covered. It is difficult to obtain the arrival time of reflection waves from the detection signal. To address this issue, the wavelet multi-scale analysis was used to analyze the discrete signal (Ren and Li 2009; Sun et al. 2014). The four scales of db6 wavelet were used to analyze the signal, the rockbolt bottom reflection time could be found in the low-frequency signal (Sun et al. 2014). The bottom reflection signal was obtained in the low-frequency component and the detail signal was obtained in the high-frequency component.

Wavelet transform is a unique time-frequency analysis method that offers multi-resolution or multi-scale analysis by decomposing the signal into different scale space to reflect the different frequency components of the signal (Ren and $\mathrm{Li}$ 2009; Sun et al. 2014). By selecting the appropriate scaling factor and moving factor, we can obtain a telescoping window and choose the appropriate wavelet, so that the wavelet transform has the ability to characterize the local characteristics of the signal in both the time and frequency domains.

The wavelet is generated by a function $\psi(t)$ through moving and telescoping and satisfies the condition of $\int_{-\infty}^{+\infty} \psi(t)=0$.

$\psi_{a, b}(t)=|a|^{-1 / 2} \psi\left(\frac{t-b}{a}\right), a, b \in R, a \neq 0$

where, $\psi(t)$ is the base wavelet or mother wavelet; $a$ is the scaling factor, and $b$ is the moving factor. The function $f(t)$ in $L^{2}(R)$ is expanded under the wavelet basis, and this expansion is called the wavelet transform of $f(t)$. Its expression is:

$W f(a, b)=|a|^{-1 / 2} \int_{-\infty}^{+\infty} f(t) \psi^{*}\left(\frac{t-b}{a}\right) \mathrm{d} t$

It can be seen from Eq. (8), the wavelet transform makes the inner product of the signal to be analyzed and a group of wavelet function clusters, and transforms the time function into the time-scale phase plane to extract some characteristics of the original signal in scale (frequency) and position (time).

Of different methods of wavelet analysis, the Daubechies wavelet series offers good compactly supported, smoothness, and approximate symmetry. It is widely used to analyze nonstationary signal. Here, we selected db6 as the wavelet basis and performed 5-layer decomposition to obtain the highfrequency and low-frequency components.

\section{Test design}

\subsection{Specimen design}

Ribbed rockbolts with $25 \mathrm{~mm}$ diameter and $2500 \mathrm{~mm}$ length were used and the rock mass that would be reinforced was simulated with a hollow cylinder made of concrete. The diameter and length of the hollow cylinder were 150 and $1500 \mathrm{~mm}$, respectively. The embedment length of rockbolt was $1500 \mathrm{~mm}$. The details of the testing sample preparation were presented in Fig. 2.

The specimen was a hollow cylinder made of $\mathrm{C} 40$ concrete, which consisted of: (i) ordinary Portland cement with a standard 28-day compressive strength of $42.5 \mathrm{MPa}$; (ii) tap water; (iii) natural river sand (the main ingredient is silica) fine aggregates of diameters from 0.3 to $1.18 \mathrm{~mm}$; and (iv) cobblestone coarse aggregates of diameters from 5 to $20 \mathrm{~mm}$ mixed at a ratio of 1:0.47:1.3:3.02.

The grout was the cement based mixture which consisted of: (i) ordinary Portland cement with a standard 28-day compressive strength of $42.5 \mathrm{MPa}$; (ii) tap water; and (iii) natural river sand (the main ingredient is silica) fine aggregates of diameters from 0.3 to $0.6 \mathrm{~mm}$.

Pre-investigation pullout test results showed that rockbolt may fail from the bolt shank when high-strength cement mortar was used to grout rockbolt and hollow cylinder specimen. Therefore, to ensure that debonding occurred before the bolt shank failed the cement mortar was prepared at a mix proportion of cement:water:fine aggregate of 1:1:3.2. The mix proportions of the cement mortar and concrete in the test are listed in Table 2.

The procedures of the sample preparation for the pullout test of the rockbolt were as follows (Ren and Li 2009). Firstly, the casting mould was made by placing the plain round bar with a diameter of $40 \mathrm{~mm}$ in the center of the cylindrical steel tube. Then the concrete mixture was poured into the mould to form the confining medium followed by be vibrated using a poker vibrator. After $48 \mathrm{~h}$ curing of the concrete, the plain round bar and the cylindrical steel tubes were removed. Finally, the rockbolts were grouted in the borehole, and 28 days later pull-out tests were conducted.

\subsection{Test procedure}

The PTM was designed and manufactured to conduct the rockbolt pull-out test with monitoring of the stress wave propagation in the rockbolt (Yu et al. 2019a, b). The pull-out load was applied to the rockbolt by a hollow jack with $300 \mathrm{kN}$ loading capacity. The schematic diagram of grouted rockbolt systems was shown in Fig. 2b. Piezoelectric sensors (TH-GP) and ultrasonic emission source (TH-F) were produced by Xiangtan Tianhong Testing Technology Co., Ltd (China). The emission voltages of the ultrasonic emission source were 100-1000 V. The piezoelectric sensor was used as the receiving or excitation sensor which could excite 10 -cycles sine wave packets with 


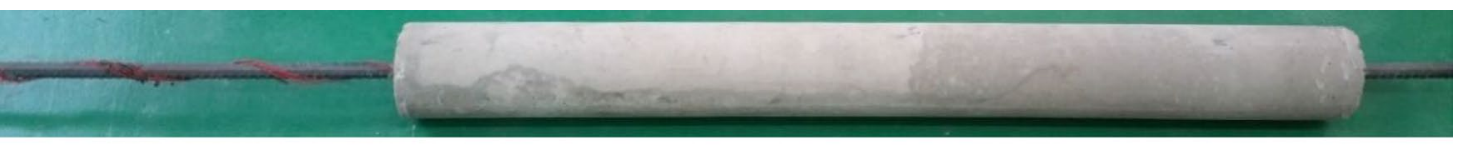

(a) Photograph of rockbolt specimen

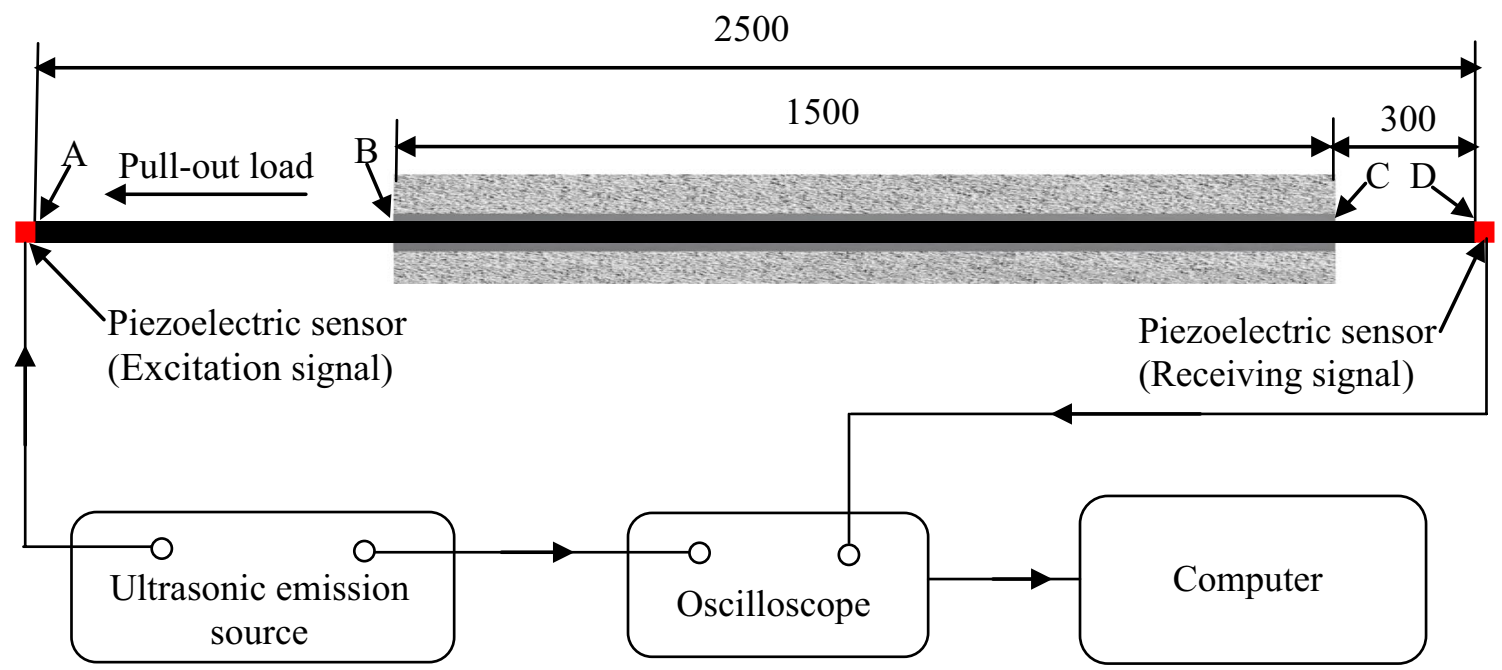

(b) Schematic diagram of experimental system

Fig. 2 The schematic diagram for detection of guided wave propagation in grouted rockbolt system (unit: $\mathrm{mm}$ )

the main frequency of $22 \mathrm{kHz}$. An ultrasonic excitation sensor was contacted to the loading end (A-end in Fig. 2b) of the rockbolt through a coupling agent (such as Vaseline) to generate the signal that was received at the free end (D-end in Fig. 2b) of the rockbolt by the receiving sensor.

The testing procedure was as follows. First, the grouted rockbolt was maintained without pull-out force. The ultrasonic excitation sensor was used to excite the ultrasonic guided wave at the A-end and the wave was received by the receiving sensor at the D-end. Next, the pull-out load was increased to $100 \mathrm{kN}$ and the above steps were repeated. Finally, the rockbolt was pulled until it was completely debonded from the concrete specimen and the ultrasonic guided wave was tested according to above steps.

\section{Experimental results and discussion}

\subsection{Wavelet multi-scale analysis}

In the schematic diagram presented in Fig. $2 b$, the B-end is the bond front-end and the $\mathrm{C}$-end is the bond backend. The continuous wavelet transform was used to convert ultrasonic $\mathrm{TiAl}$ and ${ }^{40} \mathrm{Cr}$ diffusion bonding interface signals into time-scale domain to evaluate the bonding quality (Luan et al. 2011). Therefore, the multi-scale decomposition of the wavelet transform was used in the paper to evaluate the debonding length. In Fig. 3 the multi-scale decomposition of the wave in the rockbolt under different pull-out loads is shown, where ' $s$ ' is the original signal, 'a5' is the fifth layer approximated signal, and ' $\mathrm{d} 1-\mathrm{d} 5$ ' are decomposition signals. Figure 3 a shows the wavelet multi-scale decomposition of guided wave signals in rockbolt free of pull-out load, the time $\left(t_{0 \mathrm{kN}}\right)$ required for the first wave front to arrive at the D-end was $0.604 \mathrm{~ms}$. The wave velocity $\left(c_{0}\right)$ in the free rockbolt section was $5100 \mathrm{~m} / \mathrm{s}$, thus the guided wave propagation time along the $1 \mathrm{~m}$ free length of the rock bolt was calculated according to

$t_{0}=1 / c_{0}=0.196(\mathrm{~ms})$

The wave velocity in the embedment section of the rockbolt was then calculated as

$c_{0 \mathrm{kN}}=1.5 /\left(t_{0 \mathrm{kN}}-t_{0}\right)=3676(\mathrm{~m} / \mathrm{s})$

The high-frequency signals reflected the details of the guided waves, but the $\mathrm{d} 1$ and $\mathrm{d} 2$ signals are more chaotic, so $\mathrm{d} 3$ signal was selected to pick up the wave arrival time. The time $\left(t_{0 \mathrm{kN} \text { - B }}\right)$ to receive the echo signal from the B-end at the $\mathrm{D}$-end was $1.457 \mathrm{~ms}$. Therefore, the time required to 


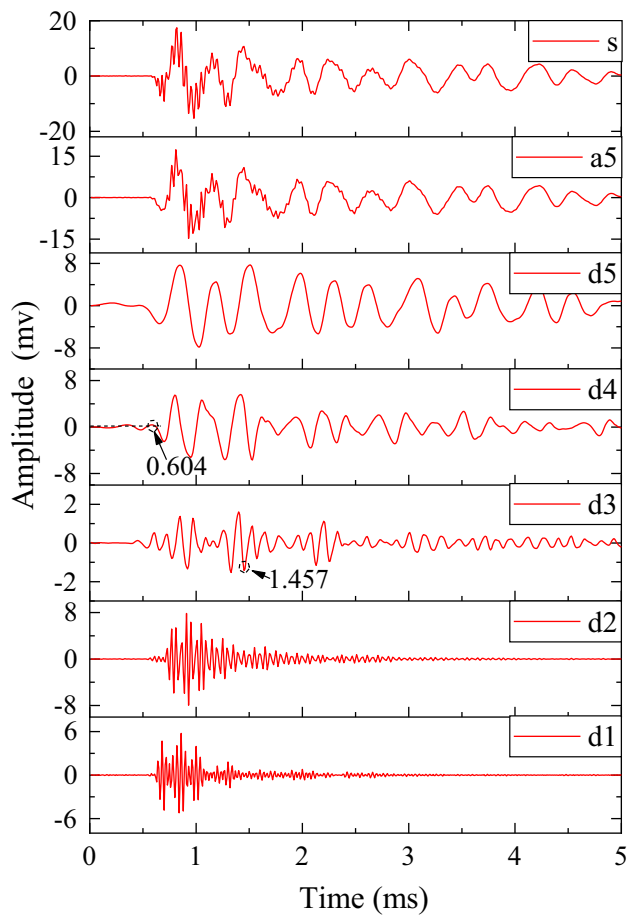

(a) $0 \mathrm{kN}$

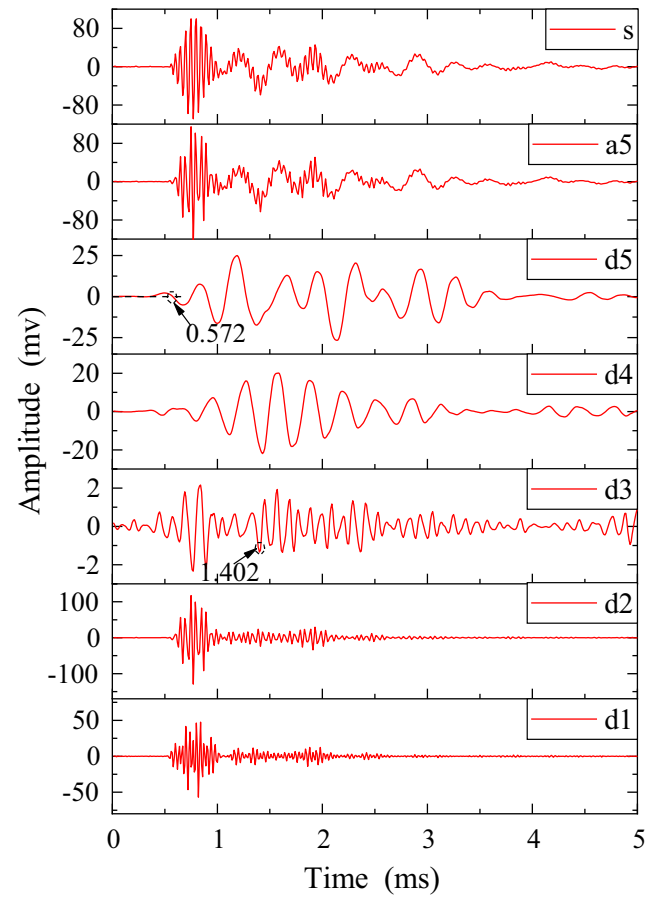

(b) Complete debonding

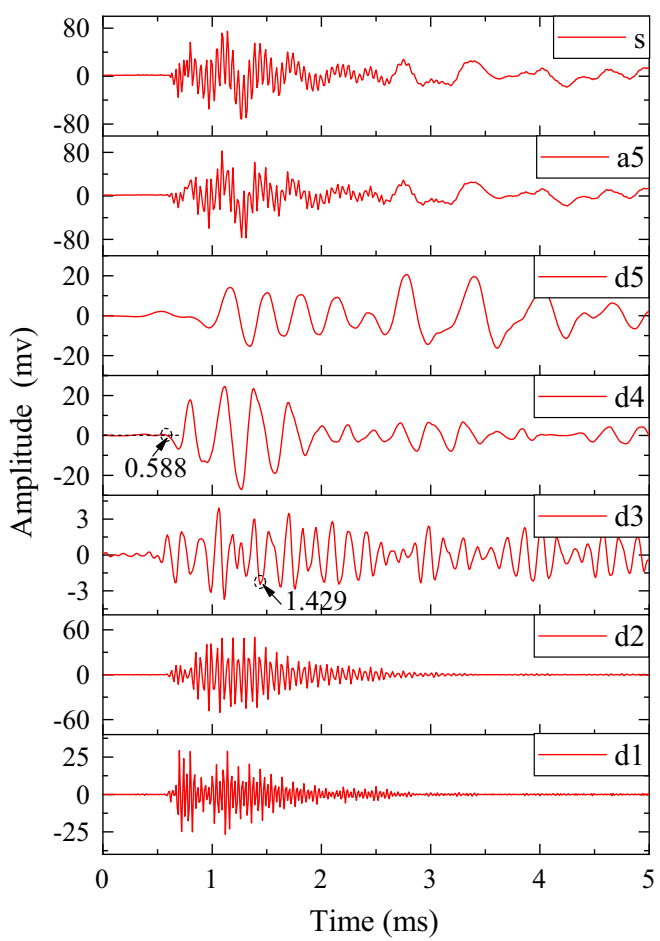

(c) $100 \mathrm{kN}$

Fig. 3 Wavelet multi-scale decomposition of guided wave signals in rockbolt under different pull-out loads 
propagate from the $\mathrm{D}$-end to the $\mathrm{B}$-end and then reflect back to the $\mathrm{D}$-end was equal to

$t_{0 \mathrm{kN}-\mathrm{B}-\mathrm{D}}=t_{0 \mathrm{kN}-\mathrm{B}}-t_{0 \mathrm{kN}}=0.853(\mathrm{~ms})$

There was $0.3 \mathrm{~m}$ free segment at the $\mathrm{D}$-end, so the bond length could be calculated as

$L_{0 \mathrm{kN}}=\left(\frac{t_{\text {OkN-B-D }}}{2}-\frac{0.3}{c_{0}}\right) c_{0 \mathrm{kN}}=1.35(\mathrm{~m})$

which was $10 \%$ different from the actual bond length of $1.5 \mathrm{~m}$.

The time $\left(t_{0 \mathrm{kN}-\mathrm{A}}\right)$ to receive the echo signal from the A-end at the D-end was $1.764 \mathrm{~ms}$. The time difference between the A-end and B-end echo signals received at the D-end was equal to

$t_{0 \mathrm{kN}-\mathrm{A}-\mathrm{B}}=t_{0 \mathrm{kN}-\mathrm{A}}-t_{0 \mathrm{kN}-\mathrm{B}}=0.307(\mathrm{~ms})$

Thus, the distance from the A-end to the B-end was calculated:

$L_{0 \mathrm{kN}-\mathrm{AB}}=\frac{t_{0 \mathrm{kN}-\mathrm{A}-\mathrm{B}}}{2} c_{0}=0.78(\mathrm{~m})$

which was for $11.4 \%$ difference from the actual length of $0.7 \mathrm{~m}$.

Figure $3 \mathrm{~b}$ presents the wavelet multi-scale decomposition of guided wave signals after completely debonding of rockbolt, the time ( $t_{\text {debonding }}$ ) for the first wave front to arrive at the D-end was $0.572 \mathrm{~ms}$, the wave velocity in the grouted system was calculated as

$c_{\text {debonding }}=1.5 /\left(t_{\text {debonding }}-t_{0}\right)=3989(\mathrm{~ms})$

The time $\left(t_{\text {debonding - B }}\right)$ to receive the echo signal from the B-end at the D-end was $1.402 \mathrm{~ms}$. Therefore, the time required for the eave to propagate from the $\mathrm{D}$-end to the B-end and then to reflect back to the D-end was equal to:

$t_{\text {debonding-B-D }}=t_{\text {debonding-B }}-t_{\text {debonding }}=0.83$ (ms)

Allowing for calculation of the bond length, it was:

$L_{\text {debonding }}=\left(\frac{t_{\text {debonding-B-D }}}{2}-\frac{0.3}{c_{0}}\right) c_{\text {debonding }}=1.42(\mathrm{~m})$

which was for $5.3 \%$ difference with the actual bond length of $1.5 \mathrm{~m}$.

The time ( $\left.t_{\text {debonding - A }}\right)$ to receive the echo signal from the A-end at the D-end was $1.675 \mathrm{~ms}$. Therefore, the time difference between the A-end and B-end echo signals received at the D-end was:

$t_{\text {debonding-A-B }}=t_{\text {debonding-A }}-t_{\text {debonding-B }}=0.273(\mathrm{~ms})$

The distance from the A-end to the B-end was:
$L_{\text {debonding-AB }}=\frac{t_{\text {debonding-A-B }}}{2} c_{0}=0.696(\mathrm{~m})$

which was for $0.6 \%$ difference with the actual length of $0.7 \mathrm{~m}$.

Figure $3 \mathrm{c}$ shows the wavelet multi-scale decomposition of guided wave signals under $100 \mathrm{kN}$ of pull-out load, the time $\left(t_{100 \mathrm{kN}}\right)$ of the first wave front to arrive at the D-end was $0.588 \mathrm{~ms}$. The time $\left(t_{100 \mathrm{kN} \text { - } \mathrm{B}}\right)$ to receive the echo signal from the $\mathrm{B}$-end at the $\mathrm{D}$-end was $1.429 \mathrm{~ms}$. Therefore, the time required to propagate from the $\mathrm{D}$-end to the $\mathrm{B}$-end and then reflect back to the $\mathrm{D}$-end was equal to:

$t_{100 \mathrm{kN}-\mathrm{B}-\mathrm{D}}=t_{100 \mathrm{kN}-\mathrm{B}}-t_{100 \mathrm{kN}}=0.841(\mathrm{~ms})$

The pull-out load causes a segment of rockbolt to debond from the concrete. The wave velocity of the grouted rockbolt was $3676 \mathrm{~m} / \mathrm{s}$ under unloading, and that when the rockbolt completely debonded (as shown in Fig. 3b), was 3989 m/s due to the presence of friction between rockbolt and concrete. The initial bond length of rockbolt was $1.5 \mathrm{~m}$, so the debonding length of the rockbolt from the loading end under $100 \mathrm{kN}$ pull-out load was equal to:

$L=\frac{c_{\text {debonding }}\left[1.5-\left(t_{100 \mathrm{kN}}-t_{0}\right) c_{0 \mathrm{kN}}\right]}{c_{\text {debonding }}-c_{0 \mathrm{kN}}}=0.752(\mathrm{~m})$

But the remaining $0.748 \mathrm{~m}$ bond length was still in the bonded state.

The debonding length of rockbolt was calculated according to the actual bond length (the distance from B-end to $\mathrm{C}$-end) of rockbolt, the wave velocity in the embeded section of the rockbolt without load and that after completely debonding, Therefore, it was impossible to predict the distance from B-end to C-end under $100 \mathrm{kN}$ load in the test.

The average wave velocity of rockbolt in the grouted system was calculated as $3826 \mathrm{~m} / \mathrm{s}$. The time $\left(t_{100 \mathrm{kN}-\mathrm{A}}\right)$ to receive the echo signal from the $\mathrm{A}$-end at the $\mathrm{D}$-end was $1.706 \mathrm{~ms}$. Therefore, the time difference between the A-end and $\mathrm{B}$-end echo signals received at the D-end was:

$t_{100 \mathrm{kN}-\mathrm{A}-\mathrm{B}}=t_{100 \mathrm{kN}-\mathrm{A}}-t_{100 \mathrm{kN}-\mathrm{B}}=0.277(\mathrm{~ms})$

The distance from the A-end to the B-end was calculated as

$L_{100 \mathrm{kN}-\mathrm{AB}}=\frac{t_{100 \mathrm{kN}-\mathrm{A}}-t_{100 \mathrm{kN}-\mathrm{B}}}{2} c_{0}=0.706(\mathrm{~m})$

and the difference with the actual length of $0.7 \mathrm{~m}$ was $0.9 \%$.

The comparison between the actual bonding length of rockbolt and that determined by ultrasonic wave is presented in Fig. 4. For the lengths from the A-end to the B-end determined by the ultrasonic wave propagation data, they were $0.78,0.706$, and $0.696 \mathrm{~m}$, respectively, under $0 \mathrm{kN}$ pullout load, $100 \mathrm{kN}$ pull-out load, and completely debonding 


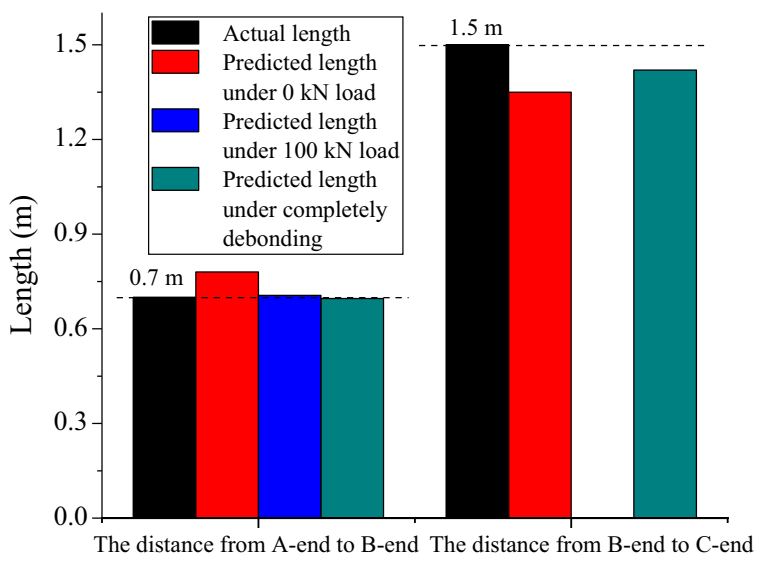

Fig. 4 The comparison between actual bond length and the length obtained based on wave propagation analysis

conditions, leading to the relative differences to the actual $0.7 \mathrm{~m}$ length of $11.4 \%, 0.9 \%$, and $0.6 \%$, respectively. Under free and completely debonding condition, the lengths from the $\mathrm{B}$-end to the $\mathrm{C}$-end determined by the ultrasonic wave propagation data were $1.35 \mathrm{~m}$ and $1.42 \mathrm{~m}$, respectively, resulting in the relative differences with the actual length of $1.5 \mathrm{~m}$ of $10 \%$ and $5.3 \%$, respectively. However, under $100 \mathrm{kN}$ of pull-out load, the length from the B-end to the $\mathrm{C}$-end could not be determined as it was calculated by back analysis.

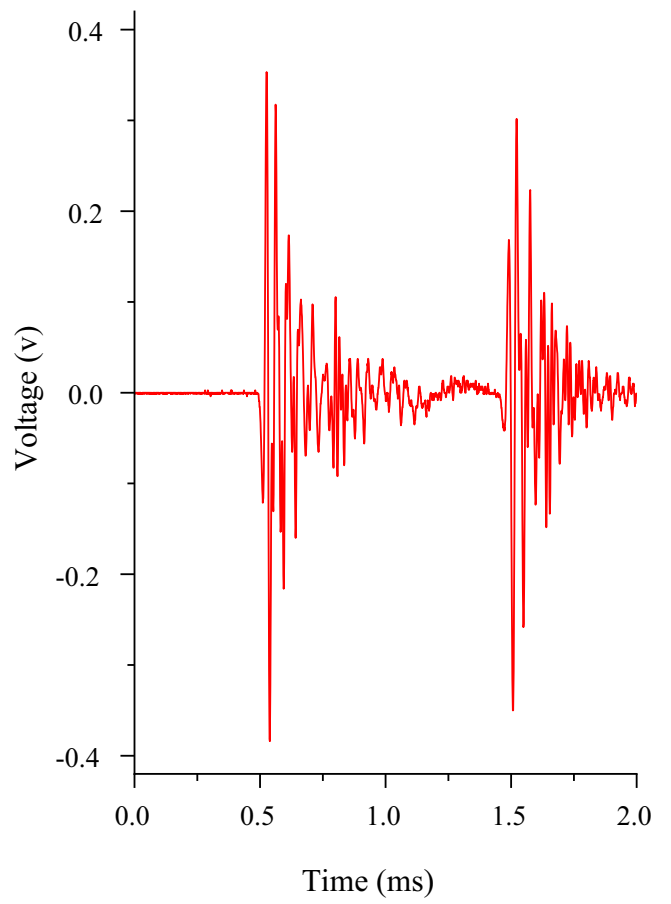

\subsection{Spectrum analysis}

The frequency of the ultrasonic guided wave signal is significantly important for analyzing the wave propagation in rockbolts. Fourier transform is used to analyze the frequency domain of the received signals. Through the Fourier transform, the signals are decomposed into different spectra. The Fourier transform is the integral of $f(t)$ with respect to $t$ ranging from $-\infty$ to $+\infty$. Namely,

$F(\omega)=\int_{-\infty}^{+\infty} f(t) e^{-i \omega t} \mathrm{~d} t$

where, $f(\omega)$ is the Fourier transform of $f(t), i$ is $\sqrt{-1}$, and the frequency variable $\omega$ is the angular frequency.

The time domain and frequency domain characteristics of wave propagation in free rockbolt are shown in Fig. 5. In the time domain, due to the influence of various factors (such as the coupling effect between rockbolt and transducer, wires and acquisition module) (Zhang et al. 2006), the guided wave energy in free rockbolt dissipated greatly and the amplitude attenuated quickly. In the frequency domain, the main frequency of the guided wave in free rockbolt was $22 \mathrm{kHz}$. Therefore, in the following numerical simulation, an idealized 10-cycles sine wave packets with the main frequency of $22 \mathrm{kHz}$ is input as the excitation signal.

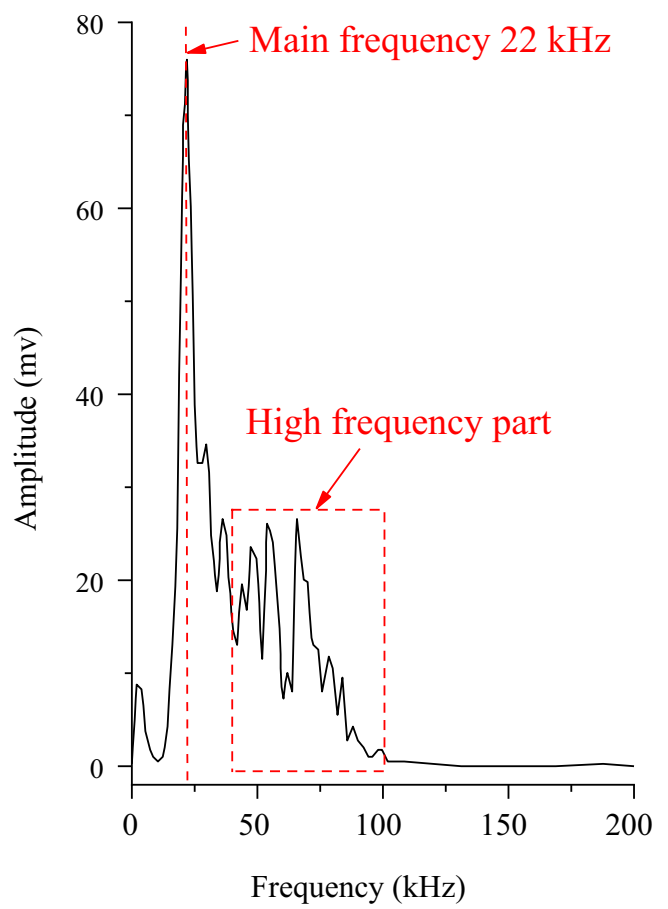

Fig. 5 Time domain and frequency domain characteristics in free rockbolt 
Time-frequency analysis has often used to analyze dispersive wave signals (Kishimoto et al. 1995; Neild et al. 2003). Figure 6 shows the time and frequency domain characteristics of the grouted rockbolt under different pull-out loads. In the time domain, the amplitude of the received signal at the D-end of the rockbolt gradually increased with the pull-out load applied on the rockbolt from 0 to $100 \mathrm{kN}$, until the completely debonding of rockbolt, which indicated maximal energy dissipation because of the good bond condition. In contrast, the amplitude of the received signal was highest when the rockbolt was completely debonded, because the interface bonding between rockbolt and cement mortar was relatively loose, and the energy only was transmitted by the friction, which means that the energy dissipation into the concrete was minimum during wave propagation and thus the bond quality was the worst.

It can be seen from the waveform under $0 \mathrm{kN}$ pull-out load, the first received signal in the D-end was severely attenuated and the guided wave packet disappeared. As the pull-out load increased to $100 \mathrm{kN}$, the debonding developed further and the guided wave packet gradually appeared due to the weakening energy attenuation.

In the frequency domain, under $0 \mathrm{kN}, 100 \mathrm{kN}$ pullout load, and under completely debonding condition of rockbolt, there were two different frequency bands in the rockbolt, and there was missing frequency band appeared between the these two bands. This was a kind of notch frequency phenomenon, which was observed by Kwun et al. (1998) and Liu et al. (2017). As the pull-out load on the rockbolt increased, the amplitude of the lowfrequency part decreased and that of the high-frequency part increased. Under $0 \mathrm{kN}$ pull-out load, at the higher frequency, ultrasonic waves experienced a greater number of interactions with the rockbolt and concrete, which implied higher attenuation (Carrión et al. 2017) and denoted the better bond quality. Therefore, we defined the amplitude ratio $(Q)$ of low frequency $\left(F_{\text {low }}\right)$ to high frequency $\left(F_{\text {high }}\right)$, namely $Q=F_{\text {low }} / F_{\text {high }}$, to quantify rockbolt. The $Q$ values were $6.14,1.31$, and 0.97 under $0 \mathrm{kN}$, $100 \mathrm{kN}$ pull-out load, and under completely debonding condition, respectively. The relationship between the $Q$ value and the debonding length of rockbolt under various pull-out loads was shown in Fig. 7. Although the test data was limited, we have tried to use a variety of curves to fit the test data, the result showed that the exponential curve was the most consistent with the data. As the $Q$ value increased, the debonding length of rockbolt decreased exponentially. This quantitative relation between bonding length and $Q$ value can be use evaluate the bonding length of rockbolts.

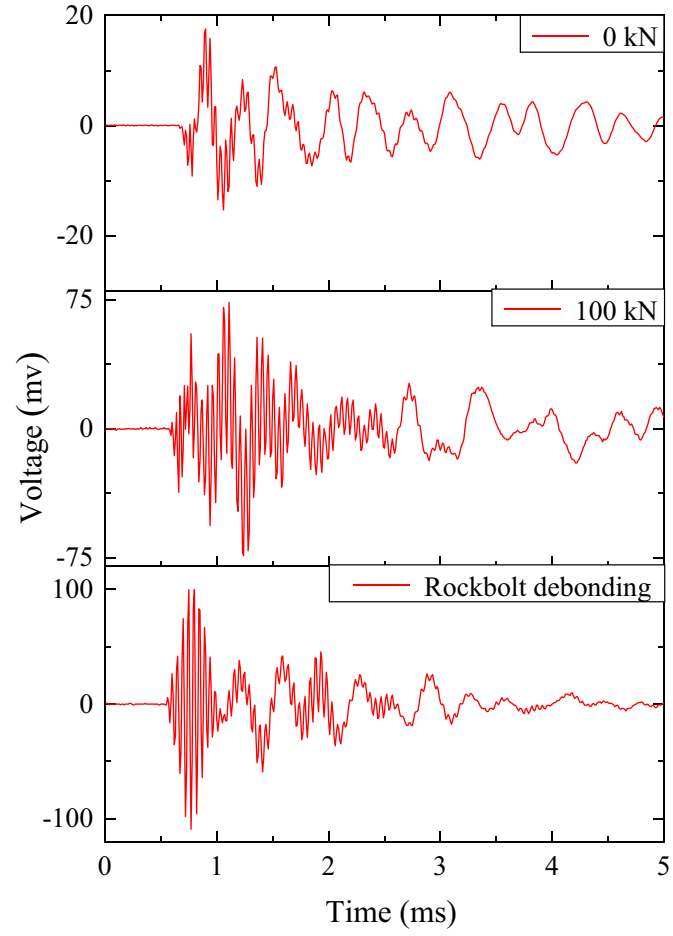

(a) Time domain

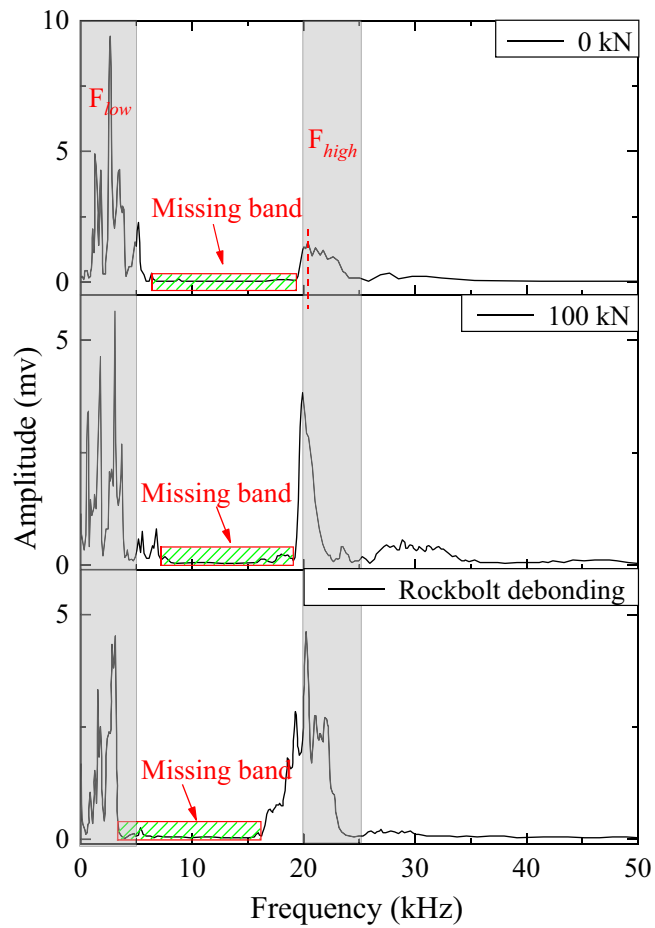

(b) Frequency domain

Fig. 6 Time domain and frequency domain characteristics in grouted rockbolt under different pull-out loads 


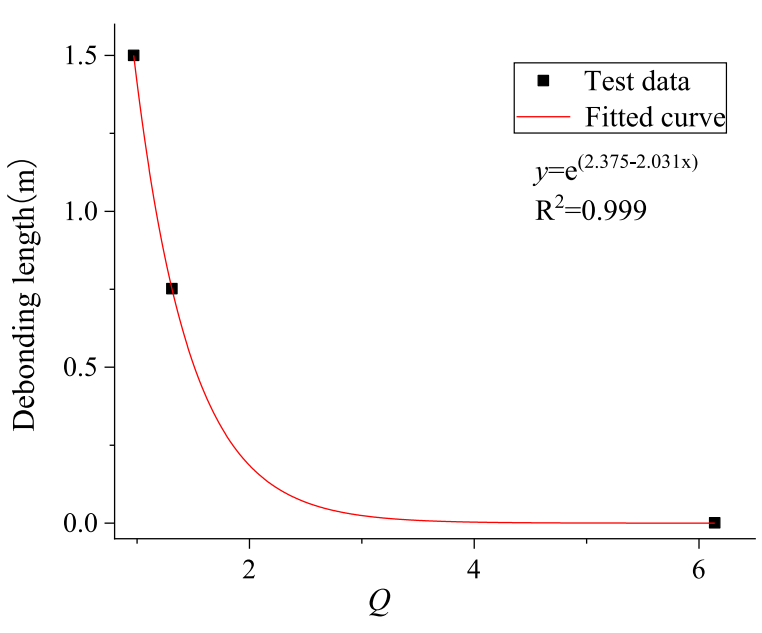

Fig. 7 Relationship between the $Q$ value and the debonding length of rockbolt under different pull-out loads

\section{Numerical analysis of guided wave propagation in grouted rockbolt}

\subsection{Numerical model of grouted rockbolt system}

The finite element software Abaqus (2014) has often been applied for numerical simulation of the debonding behaviors (Zima and Rucka 2017; Qiao and Chen 2008; Lu and Xu 2013; Chang et al. 2017; Xu et al. 2018; Chen et al. 2011; Henriques et al. 2013, 2015; Yang et al. 2017) and non-destructive testing (Zima and Rucka 2017, 2018) of grouted rockbolt system. In this section, grouted rockbolt system was simulated by four-node bilinear axisymmetric quadrilateral elements with reduced integration (CAX4R) (Fig. 8). The two-dimensional axisymmetrical model was used to simulate the debonding process of rockbolts, its effectiveness has been verified by authors in Yu et al. (2019a, b). The interface at the loaded end of the concrete is fixed during the test for the boundary condition in the rockbolt-grouted system. On the basis of extensive trials, a mesh size of $2 \mathrm{~mm}$ for the rockbolt and cement mortar and a mesh size of $5 \mathrm{~mm}$ for the concrete are deemed adequate to obtain sufficiently accurate results.

The bond behavior can be modeled by cohesive elements (Qiao and Chen 2008; Lu and Xu 2013; Chang et al. 2017; Xu et al. 2018; Park et al. 2015) or surface-based cohesive behavior (Chen et al. 2011; Henriques et al. 2013, 2015; Yang et al. 2017) using traction-separation law in Abaqus. Because the interface thickness is negligibly small, the interface bond behavior between rockbolt (concrete) and cement mortar was modeled by the surface based cohesive behavior in order to reduce the calculation time.

The cohesive behavior in the shear directions (Fig. 9) were defined as follows: the linear elastic shear stress-slip relations are defined by the elastic bond stiffness, and damage initiation criteria is met when the maximum bond shear stress is attained, and the damage evolution law for bond is assumed as exponential softening branch (Rezazadeh et al. 2017).

The uncoupled constitutive relationship of traction-separation behavior as expressed in Abaqus is as follows (Rezazadeh et al. 2017):

$T=\left\{\begin{array}{c}t_{\mathrm{n}} \\ t_{\mathrm{s}} \\ t_{\mathrm{t}}\end{array}\right\}=\left[\begin{array}{ccc}k_{\mathrm{nn}} & 0 & 0 \\ 0 & k_{\mathrm{ss}} & 0 \\ 0 & 0 & k_{\mathrm{tt}}\end{array}\right]\left\{\begin{array}{l}\delta_{\mathrm{n}} \\ \delta_{\mathrm{s}} \\ \delta_{\mathrm{t}}\end{array}\right\}=K \delta$

where, $t_{\mathrm{n}}$ is the nominal stress in the normal direction; $t_{\mathrm{s}}$ and $t_{\mathrm{t}}$ are the nominal stresses in the two local shear directions; $k_{\mathrm{nn}}, k_{\mathrm{ss}}$ and $k_{\mathrm{tt}}$ are the corresponding stiffness coefficients; and $\delta_{\mathrm{n}}, \delta_{\mathrm{s}}$ and $\delta_{\mathrm{t}}$ are the corresponding displacements.

$k_{\mathrm{nn}}, k_{\mathrm{ss}}$ and $k_{\mathrm{tt}}$ are given by (Lu and $\left.\mathrm{Xu} 2013\right)$ :

$k_{\mathrm{ss}}=k_{\mathrm{tt}}=\tau_{\mathrm{m}} / \delta_{\mathrm{m}}^{0}$

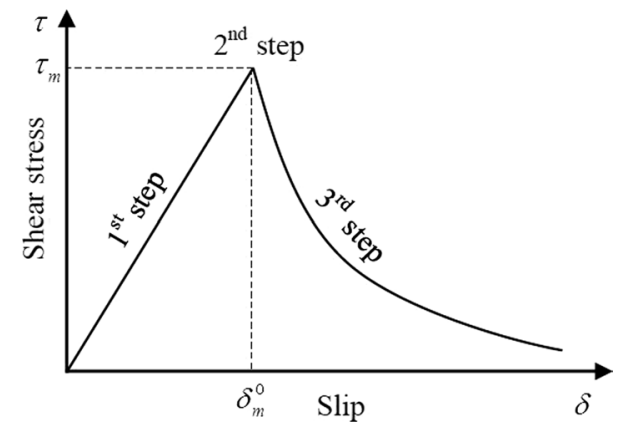

Fig. 9 Damage law for the cohesive behavior (Rezazadeh et al. 2017)

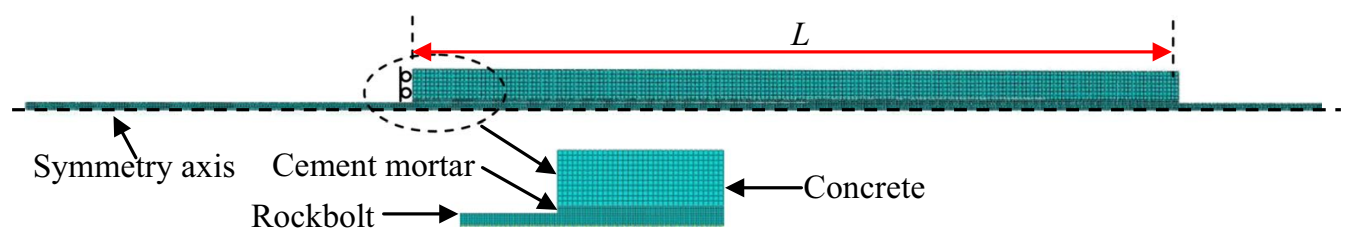

Fig. 8 Model setup for the grouted rockbolt systems 
$k_{\mathrm{nn}}=100 k_{\mathrm{ss}}=100 k_{\mathrm{tt}}$

where, $\tau_{\mathrm{m}}$ is the maximum shear strength, and $\delta_{\mathrm{m}}^{0}$ is the slip value at the maximum shear strength, or the effective displacement at the initiation of damage.

The stress components of the traction-separation model are affected by damage.

$t_{\mathrm{n}}=(1-d) \bar{t}_{\mathrm{n}}, \quad t_{\mathrm{s}}=(1-d) \bar{t}_{\mathrm{s}}, \quad t_{\mathrm{t}}=(1-d) \bar{t}_{\mathrm{t}}$

where, $\bar{t}_{\mathrm{n}}, \bar{t}_{\mathrm{s}}$ and $\bar{t}_{\mathrm{t}}$ are the stress components predicted by the elastic traction-separation behavior for the current strains without damage, $d$ is the damage variable. For exponential softening,

$d=1-\left\{\frac{\delta_{\mathrm{m}}^{0}}{\delta_{\mathrm{m}}^{\max }}\right\}\left\{1-\frac{1-\exp \left[-\alpha\left(\frac{\delta_{\mathrm{m}}^{\max }-\delta_{\mathrm{m}}^{0}}{\delta_{\mathrm{m}}^{f}-\delta_{m}^{0}}\right)\right]}{1-\exp (-\alpha)}\right\}$

where, $\delta_{\mathrm{m}}^{f}$ is the effective displacement at complete failure. $\delta_{\mathrm{m}}^{\max }$ is the maximum value of the effective displacement attained during the loading history. $\alpha$ is a non-dimensional material parameter that defines the rate of damage evolution.

In the numerical simulation, the input waveform of the ultrasonic guided wave was 10-cycles sine wave packets with the main frequency of $22 \mathrm{kHz}$ obtained by Hanning window (Fig. 10). The comparison between the numerical simulation and the experimental results of the free rockbolt was shown in Fig. 11. The modeled signal received at the other end of rockbolt was in good agreement with the test result, which indicated that the numerical model could reasonably simulate guided wave propagation in rockbolt.

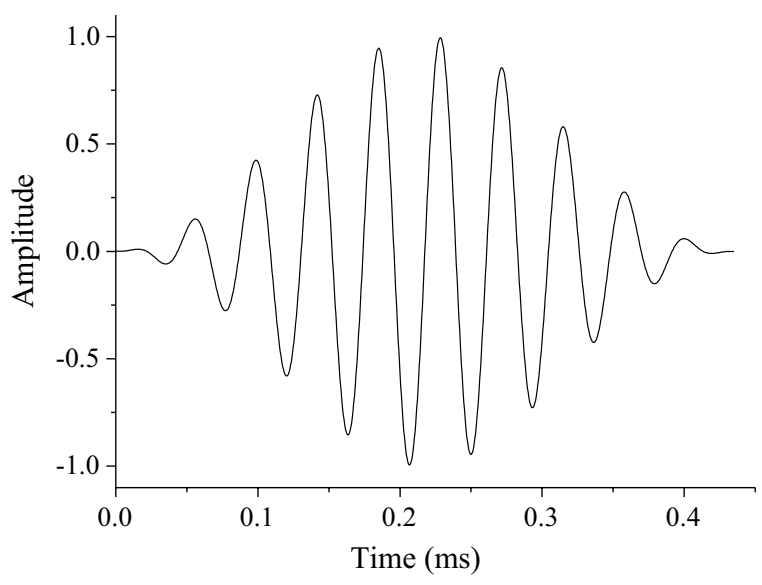

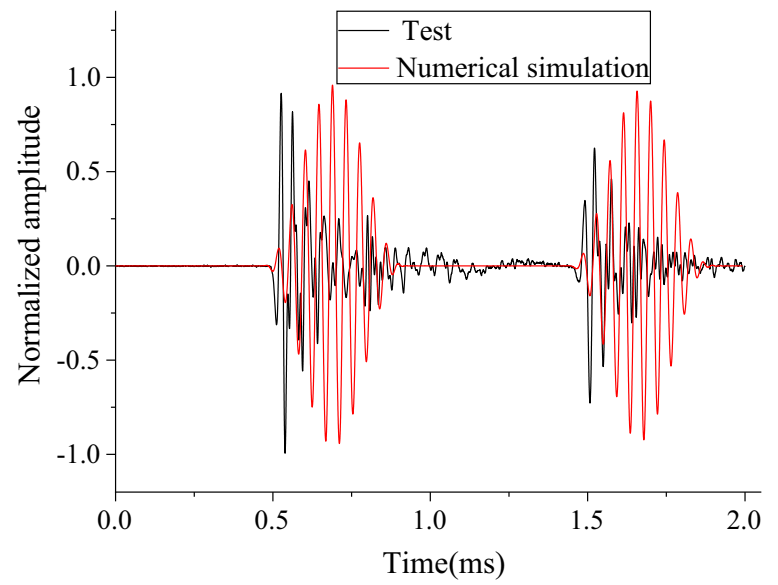

Fig. 11 Comparison of numerical and test results of wave propagation in free rockbolt

\subsection{Guided wave propagation in grouted rockbolt with different bond lengths}

Numerical simulation on guided wave propagation in grouted rockbolt with different bond lengths $(L)$ of $0.375 \mathrm{~m}$, $0.75 \mathrm{~m}, 1.125 \mathrm{~m}$, and $1.5 \mathrm{~m}$ were conducted, as shown in Fig. 8. Except for the change of bond length, the model dimensions were the same as those for the laboratory test.

\subsubsection{The effect of bond length on guided wave propagation in absence of pull-out load}

Under $0 \mathrm{kN}$ pull-out load, the guided wave propagation behaviors in grouted rockbolt with different bond lengths was determined as shown in Fig. 12. The waveform was different with that of experiments, because the bonding between the rockbolt and the cement mortar was assumed to be perfect in the numerical simulations. The guided wave had many times of transmission and reflection during propagation in the rockbolt, which resulted in the guided wave energy attenuation and the change of waveforms (Yu et al. 2019a, b). The time required to receive the B-end echo signal at the A-end (positions A, B, C, and D in Fig. 8) became shorter under the increasing bond length. That was, the closer the B-end was to the A-end, the less time required for guided wave propagated in rockbolt. The guided wave diffracted when it arrived at the B-end. Part of the wave energy reflected from the $\mathrm{B}$-end, part diffracted to the cement mortar and concrete, and the remainder propagated along the rockbolt. For the D-end echo, due to the increased bond length, the distance from the B-end to the A-end became shorter, the guided wave diffracted earlier, because the

Fig. 10 Excitation signal input for the numerical simulation 


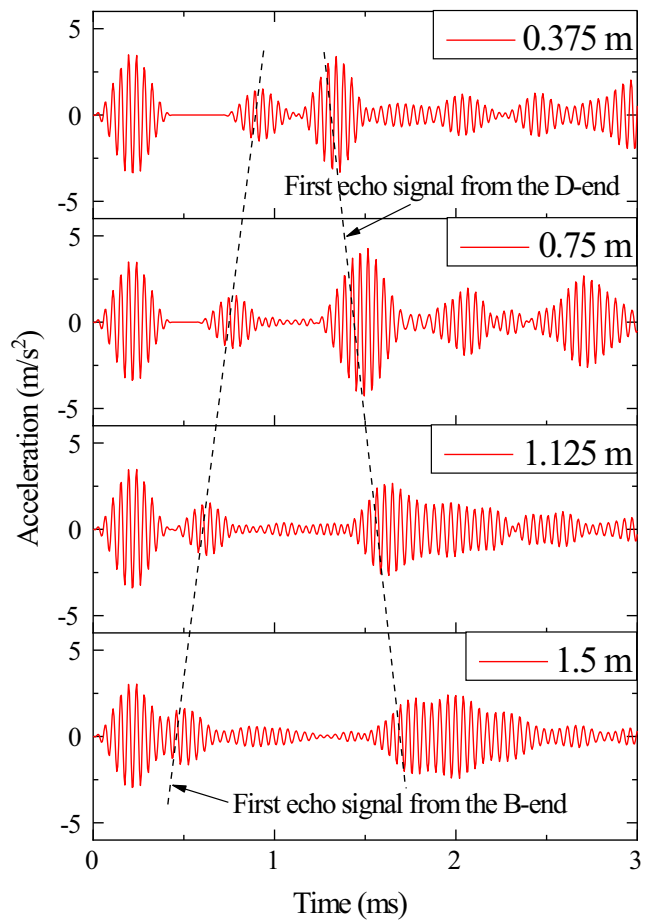

(a) A-end

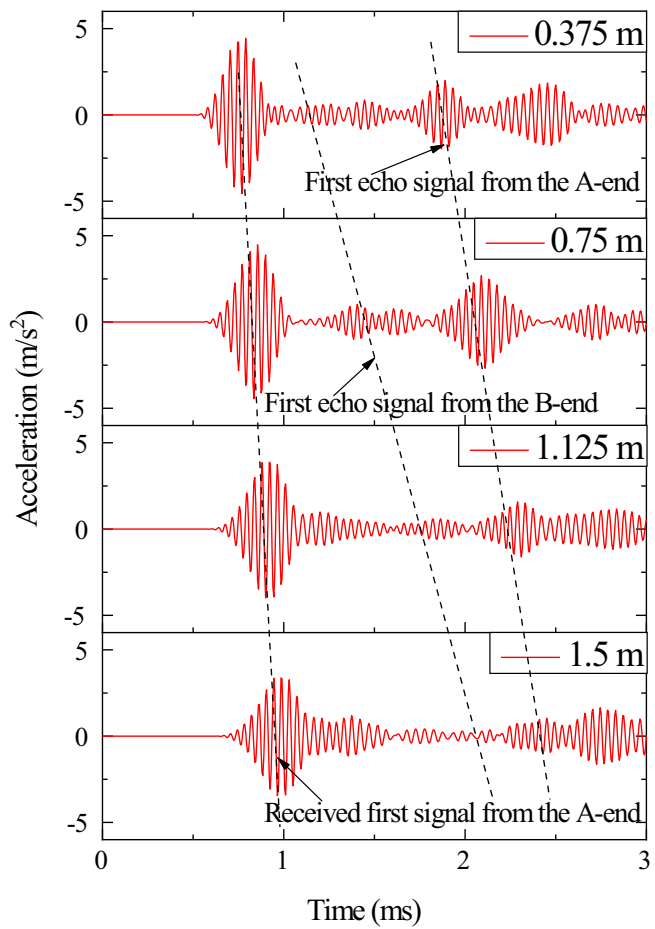

(b) D-end

Fig. 12 Wave propagation in grouted rockbolt systems with different bond lengths

guided wave energy dissipation increased, the attenuation became faster, the wave velocity decreased, and the time of received echoes was delayed accordingly. When receiving the guided wave signal at the D-end, the guide wave velocity decreased as the bond length increased. The B-end was farther away from the D-end, so the time required to receive the B-end echo signal at the D-end was delayed, as did the time required to receive the A-end echo. The rockbolt bond length could be determined by guided wave propagation time along the rockbolt and the wave velocity.

\subsubsection{The effect of pull-out load on guided wave propagation}

The guided wave signals of grouted rockbolt system with bond lengths of $0.375 \mathrm{~m}, 0.75 \mathrm{~m}, 1.125 \mathrm{~m}$, and $1.5 \mathrm{~m}$ were calculated and are shown in Fig. 13, where the pull-out load was $25 \mathrm{kN}$. The guided wave propagation is affected by pullout load. According to the wave propagation theory, the $\mathrm{B}$-end and $\mathrm{D}$-end echo signals could be detected as shown in Fig. 13. The time required to receive the B-end echo at the A-end became shorter as the bond length increased, and the signal fluctuation was more complicated, it indicated that guided wave propagation in the bond rockbolt was sensitive to the pull-out load. The time required to receive the D-end

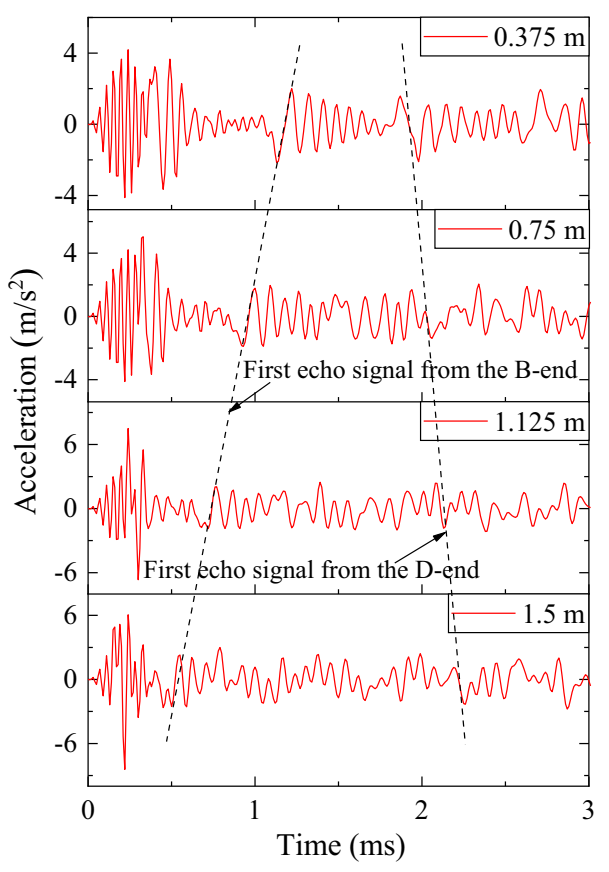

Fig. 13 Wave propagation signals with different bond lengths under $25 \mathrm{kN}$ pull-out load

echo prolonged as the bond length increased, because the wave velocity of the guided wave in the bond segment was 
slower than that in the free rockbolt. Therefore, the longer the bond length is, the slower the guide wave propagating is in the bond segment.

Figure 14 presents the guided wave propagation in the grouted rockbolt system with bond length of $1.5 \mathrm{~m}$ under different pull-out loads. When the bond length was the same, the time required to receive the B-end echo signal at the A-end was the same, but the time required to receive the D-end echo signal at the A-end became shorter as the axial load increased, because the bond state of the rockbolt changed under pull-out load. In this regard, part of rockbolt was debonded or the interface between the rockbolt and the cement mortar was in softening stage (as shown in Fig. 15). The length of debonding or softening around rockbolt increased and the bond quality of rockbolt became worse as the pull-out load increased. The guided wave propagation in

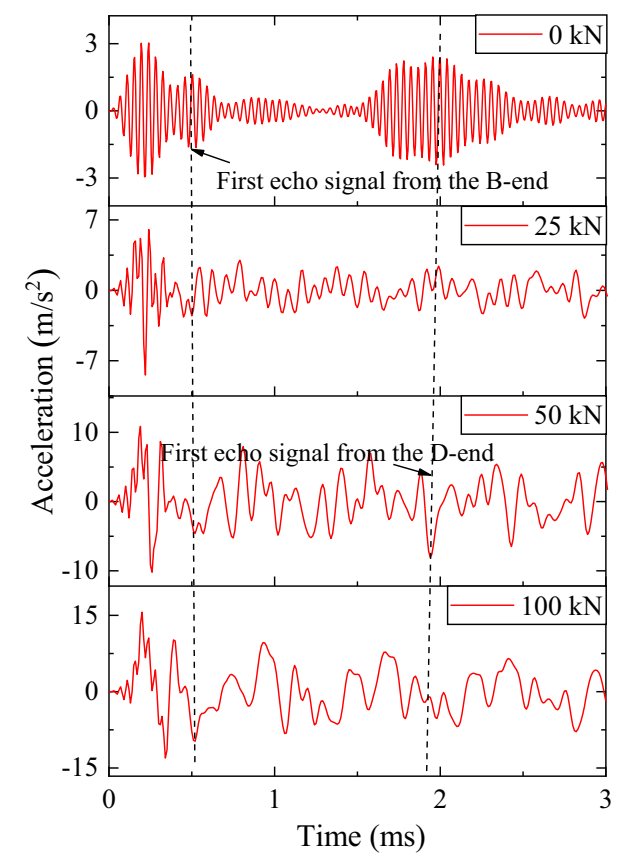

Fig. 14 Wave propagation signal with different bond length under different pull-out loads the rockbolt was in disorder, because the loading end of the rockbolt was subjected to a large concentrated force, resulting in a strong reflection of the guided wave, which made the received reflection signal extremely complex. The rockbolt was partially debonded from the cement mortar, resulting in a discontinuous interface between the rockbolt and cement mortar that interfered with the guided wave propagation.

Under the pull-out load of $25 \mathrm{kN}$, the $0.24 \mathrm{~m}$ bond length was in the softening stage (Fig. 15). Axial stress distribution along the rockbolt under $25 \mathrm{kN}$ was determined and shown in Fig. 16: the farther the distance from the B-end, the lower the axial stress. The guided wave had little diffraction when arriving at the B-end, so little energy propagated to the cement mortar and concrete, this was mainly due to the increase of the wave impedance mismatch (the low wave impedance between rockbolt and cement mortar and the high wave impedance betwee rockbolt and air) (Song and Cho 2010).

When the pull-out load was $50 \mathrm{kN}$, the bond length subjected to $50 \mathrm{kN}$ was $0.46 \mathrm{~m}$ (Fig. 15), in which $0.3 \mathrm{~m}$ was debonded and $0.16 \mathrm{~m}$ was softened. As the pull-out load increased to $100 \mathrm{kN}$, the debonding length was $0.78 \mathrm{~m}$ which was for $3.7 \%$ difference with the debonding length of $0.752 \mathrm{~m}$ based on the calculated result of wave propagation and $0.176 \mathrm{~m}$ was in the softening (Fig. 15). At the debonding area, there was a gap between the rockbolt and the cement mortar, the guided wave propagated in the rockbolt and was reflected many times at the debonding area. The propagation velocity of the guided wave in the rockbolt was higher than that in the cement mortar and concrete, guided wave partially dispersed in all directions in the cement mortar and the concrete, so that the attenuation was serious.

\section{Conclusions}

In this study, the guided wave propagation in the fully grouted rockbolt under various pull-out loads were experimented and numerically simulated to evaluate the debonding of rockbolt. The following conclusions were obtained:

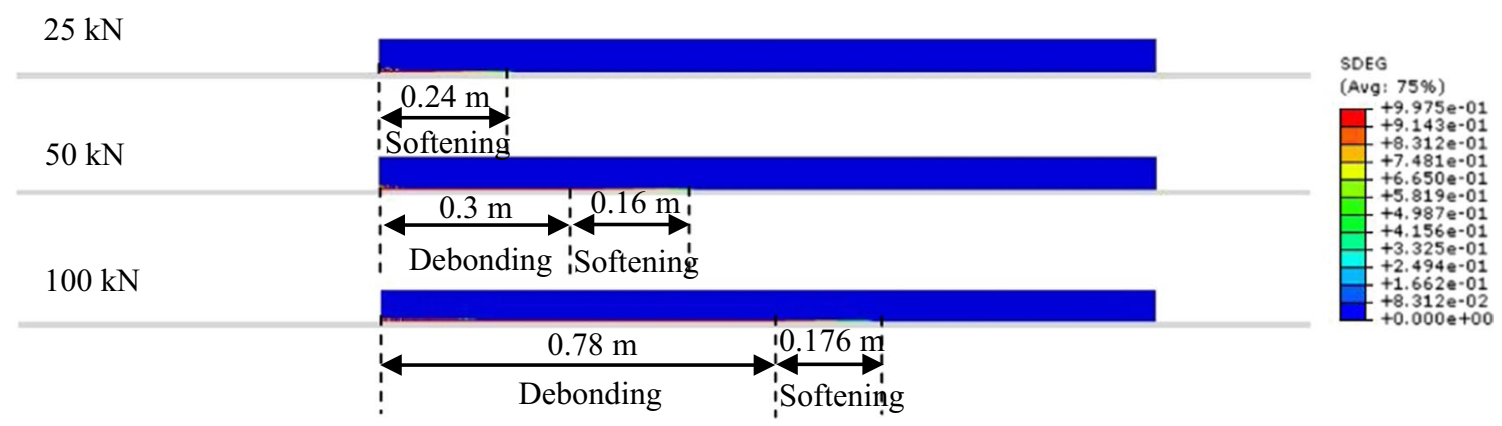

Fig. 15 Debonding and softening around rockbolt under different load level (SDEG, Scalar Stiffness Degradation) 


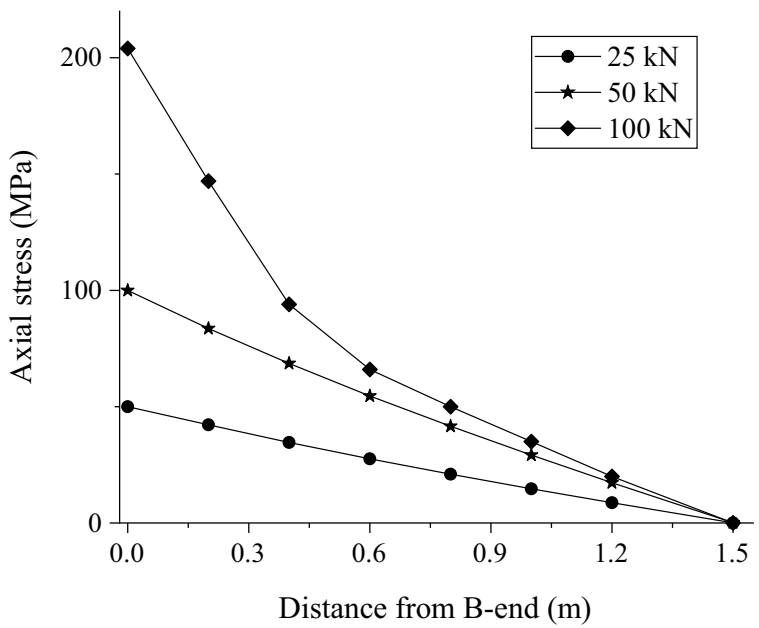

Fig. 16 Axial stress distribution along rockbolt under various pull-out loads (with $1.5 \mathrm{~m}$ bond length)

(1) Based on wavelet multi-scale analysis of guided wave signal, the debonding length of rockbolt under $100 \mathrm{kN}$ load was $0.752 \mathrm{~m}$. In the time domain, the signal amplitude increased with load from 0 to $100 \mathrm{kN}$ and until completely debonding of rockbolt, indicating maximum ultrasonic guided wave energy dissipation and best rockbolt bond quality when the rockbolt is free from loading. The energy dissipation was minimum when the rockbolt debonded completely, suggesting the worst bond quality and the largest debonding length.

(2) In the frequency domain, two different frequency bands were found in rockbolt, the amplitude of the high-frequency part increased and that of the low-frequency part decreased as the pull-out load on the rockbolt increased. The amplitude ratio $(Q)$ were $6.14,1.31$, and 0.97 under $0 \mathrm{kN}, 100 \mathrm{kN}$, and completely debonding condition, respectively. As the $Q$ value increased, the debonding length of rockbolt decreased exponentially, and vice versa.

(3) The guided wave propagation in rockbolt was very sensitive to pull-out loads. For the same bond length, under increasing pull-out load, numerical results denoted that the debonding developed gradually before the completely debonding, so did the softening of the interface between rockbolt and cement mortar. The wave impedance mismatch (the low wave impedance between rockbolt and cement mortar and the high wave impedance between rockbolt and air) increased, suggesting the longer debonding of the rockbolt.

The guided wave propagation in the rockbolt systems is very complex because the wave propagation and reflection at various interfaces exist in a mixed and complex form. This study provided basic understanding of quantifying the debonding length based on analysis of the guided wave propagation in the rockbolt system under pull-out load. As for the mining engineering application, the method can be used to detect the bond quality of rockbolt, based on which, the necessary preventive measures should be taken to ensure the stability underground mining structures. In the long run, the analysis on the complex waveform should be conducted, in order to effectively non-destructively quantify the bond quality of rockbolt.

Acknowledgements This work is funded by the National Science Foundation of China (Grant Nos. U1906208, 52104157, 51904056 and 51874069), and the Fundamental Research Funds for the Central Universities of China (Grant Nos. N2101028 and N2101015). These supports are gratefully acknowledged. The authors thank Mr. Penghui Kang and Mr. Shichang Zhou for their assistance during the laboratory test.

\section{Declarations}

Conflict of interest We declare that there is not conflict of interest.

Open Access This article is licensed under a Creative Commons Attribution 4.0 International License, which permits use, sharing, adaptation, distribution and reproduction in any medium or format, as long as you give appropriate credit to the original author(s) and the source, provide a link to the Creative Commons licence, and indicate if changes were made. The images or other third party material in this article are included in the article's Creative Commons licence, unless indicated otherwise in a credit line to the material. If material is not included in the article's Creative Commons licence and your intended use is not permitted by statutory regulation or exceeds the permitted use, you will need to obtain permission directly from the copyright holder. To view a copy of this licence, visit http://creativecommons.org/licenses/by/4.0/.

\section{References}

Beard MD, Lowe MJS (2003) Non-destructive testing of rock bolts using guided ultrasonic waves. Int J Rock Mech Min Sci 40(4):527-536

Beard MD, Lowe MJS, Cawley P (2003) Ultrasonic guided waves for inspection of grouted tendons and bolts. J Mater Civ Eng 15(3):212-218

Bouden T, Nibouche M, Djerfi F et al (2012) Improving wavelet transform for the impact-echo method of non destructive testing. Lect Not Electron Eng 141:241-247

Carrión A, Genovés V, Gosálbez J et al (2017) Ultrasonic signal modality: a novel approach for concrete damage evaluation. Cem Concr Res 101:25-32

Chaki S, Bourse G (2009a) Guided ultrasonic waves for non-destructive monitoring of the stress levels in prestressed steel strands. Ultrasonics 49(2):162-171

Chaki S, Bourse G (2009b) Stress level measurement in prestressed steel strands using acoustoelastic effect. Exp Mech 49(5):673

Chang X, Wang G, Liang Z et al (2017) Study on grout cracking and interface debonding of rockbolt grouted system. Constr Build Mater 135:665-673

Chen F, Wilcox PD (2007) The effect of load on guided wave propagation. Ultrason 47(1):111-122 
Chen HL, Wissawapaisal K (2002) Application of Wigner-Ville transform to evaluate tensile forces in seven-wire prestressing strands. J Exp Mech 128(11):1206-1214

Chen GM, Teng JG, Chen JF (2011) Finite element modeling of intermediate crack debonding in FRP-plated RC beams. J Compos Constr 15(3):339-353

Cui Y, Zou DH (2012) Assessing the effects of insufficient rebar and missing grout in grouted rock bolts using guided ultrasonic waves. J Appl Geophys 79:64-70

Dassault Systemes Simulia (2014) ABAQUS theory manual and users manuals version 6.11. USA

Hayashi T, Song WJ, Rose JL (2004) Guided wave dispersion curves for a bar with an arbitrary cross-section, a rod and rail example. Ultrasonics 41(3):175-183

Henriques J, Silva LSD, Valente IB (2013) Numerical modeling of composite beam to reinforced concrete wall joints: part I: calibration of joint components. Eng Struct 52(9):747-761

Henriques J, Gentili F, Silva LSD et al (2015) Component based design model for composite beam to reinforced concrete wall momentresistant joints. Eng Struct 87:86-104

Ivanović A, Neilson RD (2013) Non-destructive testing of rock bolts for estimating total bolt length. Int J Rock Mech Min Sci 64(12):36-43

Kishimoto K, Inoue H, Hamada M et al (1995) Time frequency analysis of dispersive waves by means of wavelet transform. Trans J Appl Mech 62(4):841-846

Kwun H, Bartels KA, Hanley JJ (1998) Effects of tensile loading on the properties of elastic-wave propagation in a strand. J Acoust Soc Am 103(6):3370-3375

Lee IM, Han SI, Kim HJ et al (2012) Evaluation of rock bolt integrity using Fourier and wavelet transforms. Tunn Undergr Space Technol 28(28):304-314

Liu X, Wu B, Qin F et al (2017) Observation of ultrasonic guided wave propagation behaviours in pre-stressed multi-wire structures. Ultrasonics 73:196-205

Lu Z, Xu Q (2013) Cohesive zone modeling for viscoplastic behavior at finite deformations. Compos Sci Technol 74(4):173-178

Luan YL, Sun T, Feng JC et al (2011) Ultrasonic evaluation of TiAl and ${ }^{40} \mathrm{Cr}$ diffusion bonding quality based on time-scale characteristics extraction. NDT\&E Int 44(8):789-796

Neild SA, Mcfadden PD, Williams MS (2003) A review of timefrequency methods for structural vibration analysis. Eng Struct 25(6):713-728

Ni QQ, Iwamoto M (2002) Wavelet transform of acoustic emission signals in failure of model composites. Eng Fract Mech 69(6):717-728

Park K, Ha K, Choi H et al (2015) Prediction of interfacial fracture between concrete and fiber reinforced polymer (FRP) by using cohesive zone modeling. Cem Concr Compos 63:122-131

Qiao PZ, Chen Y (2008) Cohesive fracture simulation and failure modes of FRP-concrete bonded interfaces. Theor Appl Fract Mech 49(2):213-225

Ren ZM, Li Y (2009) Analysis of detection signal and realization on evaluation system of bolt anchoring quality based on sound wave testing. J Chin Coal Soc 36(Supp. 1):191-196 ((in Chinese))
Rezazadeh M, Carvelli V, Veljkovic A (2017) Modelling bond of GFRP rebar and concrete. Constr Build Mater 153:102-116

Rizzo P (2006) Ultrasonic wave propagation in progressively loaded multi-wire strands. Exp Mech 46(3):297-306

Song KI, Cho GC (2010) Numerical study on the evaluation of tunnel shotcrete using the impact-echo method coupled with Fourier transform and short-time Fourier transform. Int J Rock Mech Min Sci 47:1274-1288

Suits LD, Sheahan TC, Han SI et al (2008) Evaluation of rock bolt integrity using guided ultrasonic waves. Geotech Test J 32(1):31-38

Sun KH, Hong JC, Kim YY (2006) Dispersion-based continuous wavelet transform for the analysis of elastic waves. J Mech Sci Technol 20(12):2147-2158

Sun B, Zheng XT, Zeng S et al (2014) Multi-scale analysis on anchoring defects diagnosis under multiple measuring points. J Chin Coal Soc 39(7):1385-1390 ((in Chinese))

Wang C, He W, Ning J (2009) Propagation properties of guided wave in the anchorage structure of rock bolts. J Appl Geophys 69(3):131-139

Xiao GQ, Liu TY, Zhou LM et al (2006) Application of Multi-resolution analysis in detection of rock anchor bar quality using elastic wave non-detructive method. J Yangtze River Sci Res Inst 23(4):67-70 ((in Chinese))

Xu C, Li Z, Wang S et al (2018) Pullout performances of grouted rockbolt systems with bond defects. Rock Mech Rock Eng 51(3):861-871

Yang WR, He XJ, Dai L (2017) Damage behaviour of concrete beams reinforced with GFRP bars. Compos Struct 161:173-186

Yu JD, Bae MH, Lee IM et al (2013) Nongrouted ratio evaluation of rock bolts by reflection of guided ultrasonic waves. J Geotech Geoenviron Eng 139:298-307

Yu JD, Hong YH, Byun YH et al (2016) Non-destructive evaluation of the grouted ratio of a pipe roof support system in tunneling. Tunn Undergr Space Technol 56(2016):1-11

Yu SS, Zhu WC, Niu LL et al (2019a) Experimental and numerical analysis of fully-grouted long rockbolt load-transfer behavior. Tunn Undergr Space Technol 85:56-66

Yu T, Chaix JF, Audibert L et al (2019b) Simulations of ultrasonic wave propagation in concrete based on a two-dimensional numerical model validated analytically and experimentally. Ultrasonics 92:21-34

Zhang C, Zou DH, Madenga V (2006) Numerical simulation of wave propagation in grouted rock bolts and the effects of mesh density and wave frequency. Int J Rock Mech Min Sci 43:634-639

Zima B, Rucka M (2017) Non-destructive inspection of ground anchors using guided wave propagation. Int J Rock Mech Min Sci 94:90-102

Zima B, Rucka M (2018) Guided ultrasonic waves for detection of debonding in bars partially embedded in grout. Constr Build Mater 168:124-142

Zou DHS, Cheng J, Yue R (2010) Grout quality and its impact on guided ultrasonic waves in grouted rock bolts. J Appl Geophys 72(2):102-106 